\title{
Physical therapy using robotics: A project-based learning experience for undergraduate students
}

\author{
Edgar Lopez-Caudana, Christian Fernando Lopez-Orozco, Cesar Mendoza Bárbara, Germán \\ Eduardo Baltazar Reyes, Pedro Ponce, J. Enrique Chong-Quero, \\ School of Engineering and Sciences, Tecnologico de Monterrey
}

\begin{abstract}
The dynamic society we live in requires constant adaptation and innovation on every aspect of our daily lives, allowing us to improve the necessities of different people by doing it. For this study, we used a new approach with project-based learning to go beyond the typical environment in higher education and bring solutions to real-life scenarios. The project was developed with undergraduate engineering students in collaboration with a rehabilitation institute in Mexico City to design a physical therapy routine using the NAO robot. It allowed interaction between young patients in real time and fostered empathy while developing a final usable product. The study measured the usability of the robotic platform during the rehabilitation sessions and the reproducibility of the project through Cronbach's alpha evaluation. The usability results show a higher interest in the project from both the patients and the medical staff involved while constructing the material needed to develop a product that matches the standards given by the rehabilitation institute.
\end{abstract}

Implications for practice or policy:

- Therapists could change traditional approaches to caregiving while adopting new technological methodologies using robots.

- Higher education students could supplement their school curricula with real-case scenarios such as creating innovative therapy sessions for people with physical disabilities.

- Schools might need to collaborate with a wide range of institutions to provide technological solutions to real problems.

Keywords: higher education, social robotics, project-based learning, physical therapy, educational innovation

\section{Introduction}

Nowadays, the labour market requires students to possess a wide range of skills, often referred to as 21 stcentury skills, beyond mastering the basic abilities of their specific disciplines (Zarouk et al., 2020). Therefore, universities should focus on the technical tools they provide to their students and help them to develop a wide range of soft skills for their future success in society. Furthermore, creating real-life opportunities during their professional preparation should be a must in planning curricula, allowing students to create projects to get a passing grade in the classroom, interact with society and give a higher meaning to their work. In order to match higher education with the current needs required from professionals, teachers need to develop an instructional model that focuses on enabling students to develop practical skills which they can apply to learn real-life situations (Sakulvirikitkul et al., 2020). The model would allow students to apply their knowledge on specific projects, interact with people from different professional areas and work together to achieve a mutual goal.

This study demonstrates the importance and benefits of project-based learning to solve real-life problems through designing, programming and applying a physical therapy routine using the NAO robot. NAO is a humanoid robot capable of interacting with the user through different human-like movements and programmed conversation lines. At the same time, it allows the user to interact with it through a variety of touch sensors, microphones, voice recognition or even image detection through a camera.

Undergraduate students at Tecnologico de Monterrey were asked to collaborate with the Foundation to Help the Mentally Weak (FADEM) in Mexico City to generate physical therapy exercises using robotics. FADEM is a non-profit organisation committed to improving the quality of life for children, young people and adults with intellectual disabilities. The students' main challenge was to design a series of games and activities that could be applied to a physical therapy session and then program the NAO robot to lead the 
entire session, following a series of requirements and standards that the institute has given for a wholesome routine. The students designed, programmed and interacted with the patients while manipulating the robot. This methodology allowed them to experience the results and impact of their project in real-time.

The final product presented in this study was wholly supervised and approved by specialists from FADEM. In addition, professional therapists from FADEM were in the room every time the robot was leading a therapy session, ensuring that all the exercises were done safely and following the correct standards.

\section{Literature review}

\section{Project-based learning}

As applied in this study, project-based learning refers to a dynamic approach to teaching in which students explore real-world problems and challenges (Kovalyova et al., 2016). This methodology seeks to allow the student to apply their knowledge in a project (previously established by the professor or freely designed by the student), following a series of requirements to be evaluated at the end.

Project-based learning methodology encompasses multiple approaches. For example, Aizpun et al. (2015) collaborated with Adidas and asked the students to redesign an existing product, allowing them to increase their motivation while working with them. On the other hand, Nurbekova et al. (2020) placed students of a microcontrollers programming course in groups with general topics to work on, giving them total freedom to organise themselves and complete the tasks required for their final project. Studies on accounting application in real life (Carrasco et al., 2018), project-based learning mixing professional English teaching and music (Borisova \& Letkina, 2019) and the use of the methodology to compare its differences with the traditional way of teaching in universities (Bilgin et al., 2015) are successful examples of how projectbased learning can be applied in multiple fields of study. This type of learning allows students to increase their motivation and experience, nurturing creativity with innovative ideas and other capabilities demanded by employers, such as teamwork, leadership and problem-solving skills (Ahmad Zukarnain et al., 2020).

Project-based learning encourages students to investigate questions, propose and explain the ideas by engaging in the activities as a form of situated learning based on constructivism (Wang, 2020). During the entire process, the student is given the freedom to apply their knowledge and abilities while facing the challenge proposed. Still, they have the great responsibility of working on the development and improvement of their learning. This methodology requires continuous conversation, discussion and evaluation between professors and students (Wurdinger et al., 2020). When properly applied, it improves the climate in the classrooms as well as the teacher-student relationships. Al Mulhim \& Eldokhny (2020) have suggested involving the professors' perception to identify the measures that promote successful implementation and minimise negative impacts. This suggestion means that although students are given the opportunity and freedom to develop, create and apply their knowledge, the role of the professor is to work as a supportive tool and make sure that the entire process will result in a beneficial product.

\section{Social robotics and education}

The impact of social robots has been investigated in different educational contexts, demonstrating its great potential in supporting learners and teachers (Donnermann et al., 2020). One of the main benefits of robotics in education is that it can be adapted into multiple environments and situations as learning or teaching companions for children in classrooms or at home, for the elderly to maintain cognitive and physical abilities and for learners with deficiencies to adapt content to their capabilities (Johal, 2020).

There are multiple approaches in which a robot could be a support for education. Belpaeme et al. (2018) described three different roles that the robot could use to interact and work as a tool for learning: as a teacher or a tutor, in peer-to-peer relationships and in the role of a novice. When it comes to education, the traditional approach is for the robot to work as a teacher or tutor. Nevertheless, the robot could play any of the roles or a combination. The robot's role should be established at the outset. This will allow the robot to interact according to the series of rules and statements programmed to it.

Once the educational role of the robot is decided, it is necessary to consider the moral guidelines for its responsible implementation (Smakman et al., 2021), which should be established according to the social 
environment and in consideration of people's different perspectives. The ethical evaluation (at least for the present time) should be specific to the robot (its capabilities and appearance) and the practice within which it has been placed (van Wynsberghe, 2016). A correct application of the guidelines will allow the robot to interact with its surroundings and have acceptance within the society, which is needed for it to serve as a supportive tool.

\section{NAO robot}

The NAO robot has 25 degrees of freedom, two cameras, seven touch sensors, four directional microphones and speakers, speech recognition and the ability to converse in 20 languages. These sensors and actuators make the robot capable of performing all simple human movements, such as walking forwards and backwards, sitting down and standing up, waving and playing soccer (Assad-Uz-Zaman et al., 2020).

The NAO robot has been used as a supportive tool and a centre of research in multiple areas, including education, healthcare and elderly care. In their study, Shamsuddin et al. (2012) made the robot interact with children with autism spectrum disorder to analyse their reactions. Goenaga et al. (2020), on the other hand, used the robot for their experiment as an interviewer programmed to react using five basic emotions. Studies regarding the NAO robot used for an experimental tactile conveyance to measure emotions (Andreasson et al., 2018) and speech processing (Chen et al., 2017) are clear examples of how the robot has been deployed into multiple fields during the past years. Its skills and versatility make the NAO robot the perfect candidate for introducing technology into physical therapy sessions.

The NAO robot was programmed entirely by the students with the Choregraphe software platform. This interface is a very intuitive graphical environment that allows simple programming (Pot et al., 2009). Figure 1 shows the Choreographe platform, with the series of statements required to follow the therapy session. Each of the blocks represents an action that could be a speech indication, a movement or a combination.

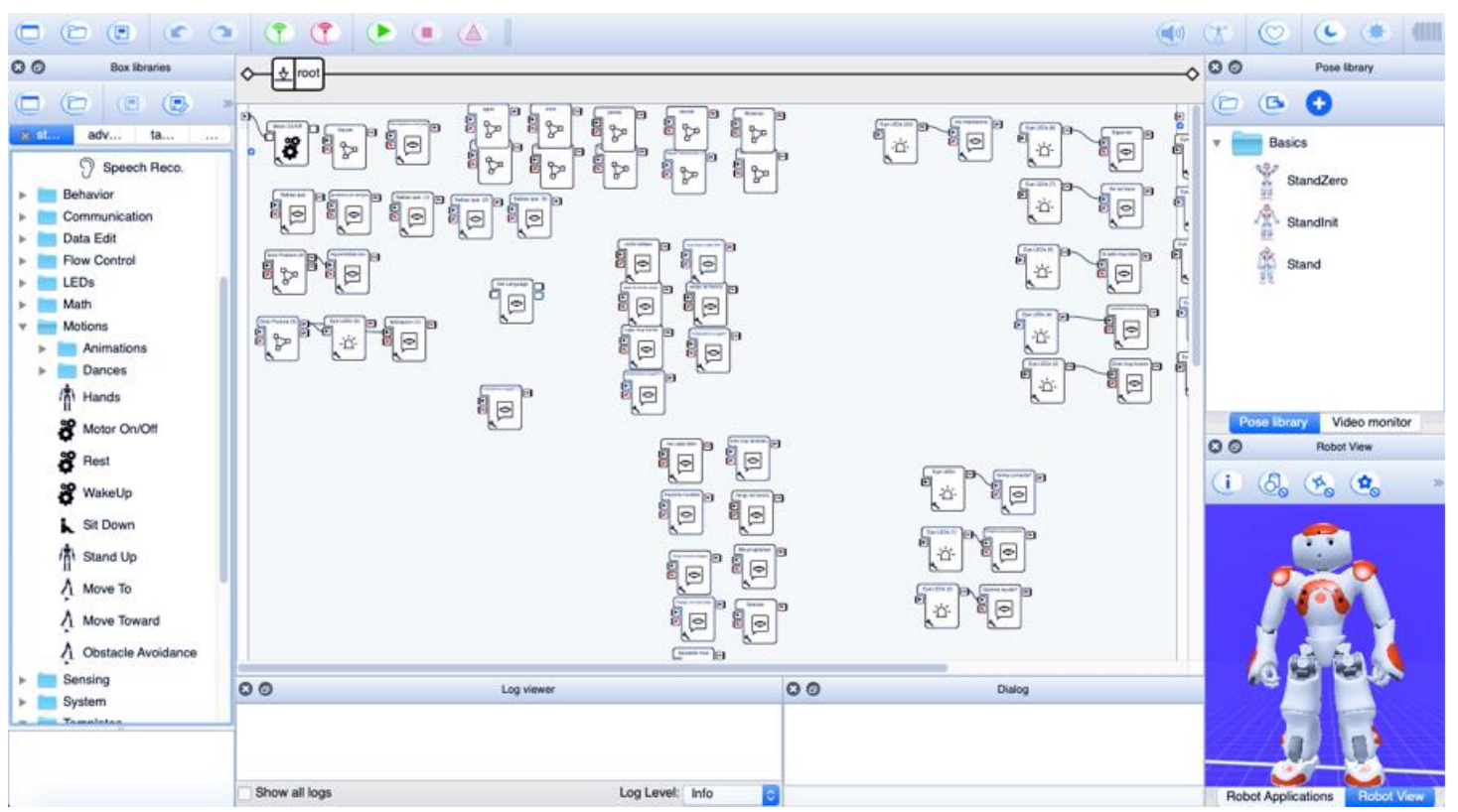

Figure 1. Choreographe environment

\section{Measurement of usability}

According to Davis (1989), it is necessary to measure the level of acceptance of any proposed model. However, since there are multiple methodologies to assess a platform's usability, it is necessary to follow concise model protocols. The unified theory of acceptance and use of technology (UTAUT) is used for evaluating a technological platform's performance expectancy and its efforts, social influences and facilitating conditions of use (Venkatesh et al., 2003). Following these four metrics, it is possible to analyse how a given population finds the ease of use and the benefits of platforms for a specific task. 
It is also essential to consider that when using surveys and questionnaires to evaluate any platform or protocol's usefulness, they need to be as concise as possible. This is because the person answering it loses focus when considering multiple questions. Heerink et al. (2009) used a simplified evaluation metric of UTAUT model with this in mind. In evaluating the usefulness of a robotic platform as an assistive tool, they reduced the complete model to ten constructs:

- the levels of anxiety produced by the use of the platform (ANX)

- how well the platform can be used in the given environment (FC)

- the easiness of the platform to adapt to the changes in its surroundings (PAD)

- the joy or pleasure of the user when using it (PENJ)

- the user's perception towards the platform's ease of use (PEOU)

- how well the robot interacts socially (PS)

- how much the robot facilitates the performance of the user's work (PU)

- how the user perceives their superior's opinion about the use of the platform (SI)

- how well the platform perceives a social entity when interacting with one (SP)

- $\quad$ how reliable the platform's performance is (Trust).

Another consideration is that a given platform's testing population, the experiments, environments, or even the platforms implemented change. It is then necessary to evaluate how well the evaluation metric's results can be replicated in different scenarios. Cronbach's alpha equation helps analyse the reproducibility and reliability of the ten constructs in a different scenario (Wadkar et al., 2016). This formula, shown in the following equation, compares the individual variance of the constructs' answers of each testing subject $\left(\sigma^{2} y_{i}\right)$ with the general variance of the whole population $\left(\sigma^{2} x\right)$ among a given number of questions $(K)$ :

$$
\alpha=\frac{K}{K-1}\left(1-\frac{\sum_{i=1}^{K} \sigma^{2} y_{i}}{\sigma^{2} x}\right)
$$

Depending on the task of the platform and the given environment, the acceptance of $\alpha$ will change. However, as mentioned by Reyes et al. (2021), when talking about an educational environment, a value of $\alpha=0.7$ or higher is considered acceptable to determine if the given results are reproducible. For this study, the same metrics of acceptance were considered.

\section{Methodology}

The proposal was implemented in 2020 with the collaboration of five members of FADEM's medical staff and eight fourth-grade engineering students from the Mechatronics and Biomedicine programmes. It originated as a social service programme in the students' university; therefore, participation was completely voluntary. During the development of the project, the students worked collaboratively with and presented their proposals and activity designs to the FADEM medical staff.

To fulfill the necessities of each individual, FADEM provided the students with information on the medical condition of each patient attending physical therapy. The project was implemented with four different patients, who presented a diagnosis of cerebral palsy or brain injury and upper limb hemiplegia. All the patients could follow directions and maintain a good attention span for a 60-minute treatment session. Informed parental and child consent was obtained before participating in the project.

Depending on the physical disability of each individual, the students were asked to design a series of games and routines following the physical routines that the FADEM therapists would typically follow daily. For each activity, the students were informed of the patient's exercises and physical capabilities. That information allowed the students to design and propose new activities to be implemented in the therapy sessions. After that, FADEM staff oversaw the therapy proposals and indicated the necessary changes in the activities. Once the exercises were accepted, the students were asked to program the NAO robot so it could explain the entire procedure and interact with the patients. The student designed a total of 24 games and exercises, shown in Table 1, where the robot would explain each routine to the patients and motivate them during the entire process. 
Table 1

Games and exercises

\begin{tabular}{|c|c|c|}
\hline No. & Exercise & Description \\
\hline 1 & Sugar & With the help of a spoon, the patient was asked to fill a plate with sugar. \\
\hline 2 & Cards & The patient was asked to flip all the cards that were previously placed on the table. \\
\hline 3 & $\begin{array}{l}\text { Chimney and } \\
\text { marbles }\end{array}$ & $\begin{array}{l}\text { A bunch of marbles was placed on the table next to a toy house. Then, the patient was } \\
\text { asked to place all the marbles into the chimney of the toy house. }\end{array}$ \\
\hline 4 & Bottle and balls & $\begin{array}{l}\text { A bottle filled with styrofoam balls was provided. The patient was asked to take the } \\
\text { objects out of the bottle and put them back multiple times. }\end{array}$ \\
\hline 5 & Tower & Pieces were given to the patient, and they were subsequently asked to build a tower. \\
\hline 6 & Columns & Pieces were given to the patient in a specific order, following colours and sizes. \\
\hline 7 & Clay & The patient was asked to mould the clay into multiple shapes. \\
\hline 8 & Jenga & The patient was asked to play the Jenga game with their instructor. \\
\hline 9 & Hanoi tower & The patient was asked to move all the rings from one location to another. \\
\hline 10 & Pulling ball & With the ball given, the patient needed to verify which pieces could be pulled. \\
\hline 11 & Flat clay & The patient was asked to flatten the clay given with their hands. \\
\hline 12 & Line & With all the pieces given, the patient was asked to organise them by their size. \\
\hline 13 & Water & A bottle with water was provided, and the patient was asked to pour it into a glass. \\
\hline 14 & Puzzle & The patient was asked to complete a puzzle of different shapes. \\
\hline 15 & Flat pieces & Multiple pieces were given to the patient; their job was to organise them by colour. \\
\hline 16 & Piggybank & A piggybank was given, and the patient was asked to put all the coins inside. \\
\hline 17 & Clean a table & A rag was given, and the patient was asked to clean the table. \\
\hline 18 & Fingers & The patient was asked to put different pieces previously given between their fingers. \\
\hline 19 & Fishing & A fishing game was given, the patient was asked to fish all the fish using a stick. \\
\hline 20 & Peg board & A board with holes was placed, and the patient needed to put pegs in them. \\
\hline 21 & Colour sticks & Different sticks were given to the patient; they were asked to organise them by colour. \\
\hline 22 & Joining stars & The patient was given a series of stars that could be joined. \\
\hline 23 & Wood pole & The patient was asked to remove a series of rings from a pole placed on the table. \\
\hline 24 & Bracelet & The patient was asked to remove the pieces of a bracelet and place them in a bottle. \\
\hline
\end{tabular}

The students developed suitable games and exercises depending on the possibilities of each patient, brought the material required for each session, managing the time allocation and manipulated the robot to complete the physical therapy sessions. Figure 2 shows the patient-robot interaction during one of the sessions.

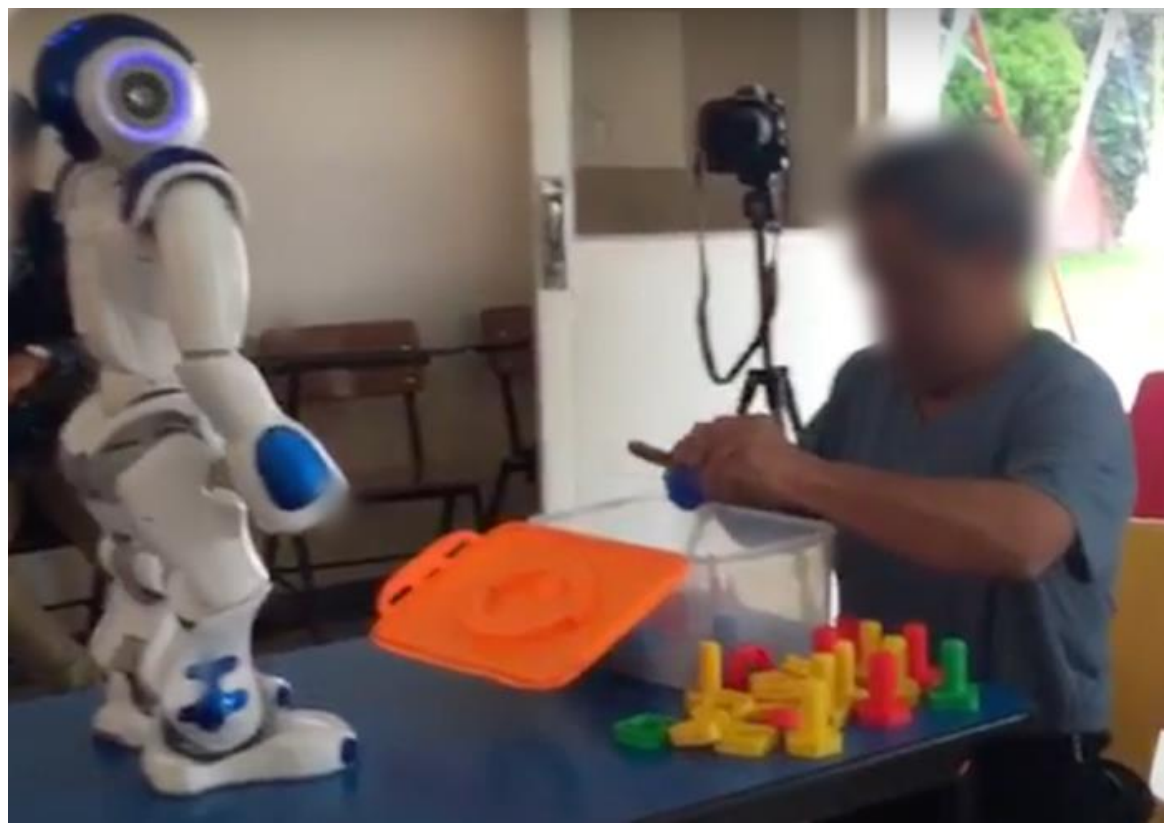

Figure 2. Tower exercise during a physical therapy session

In addition to the games, the therapists asked students to include a series of physical movements to do at the end of every session, where the robot would perform several arm movement exercises and the patient would follow its example, as shown in Figure 3. 


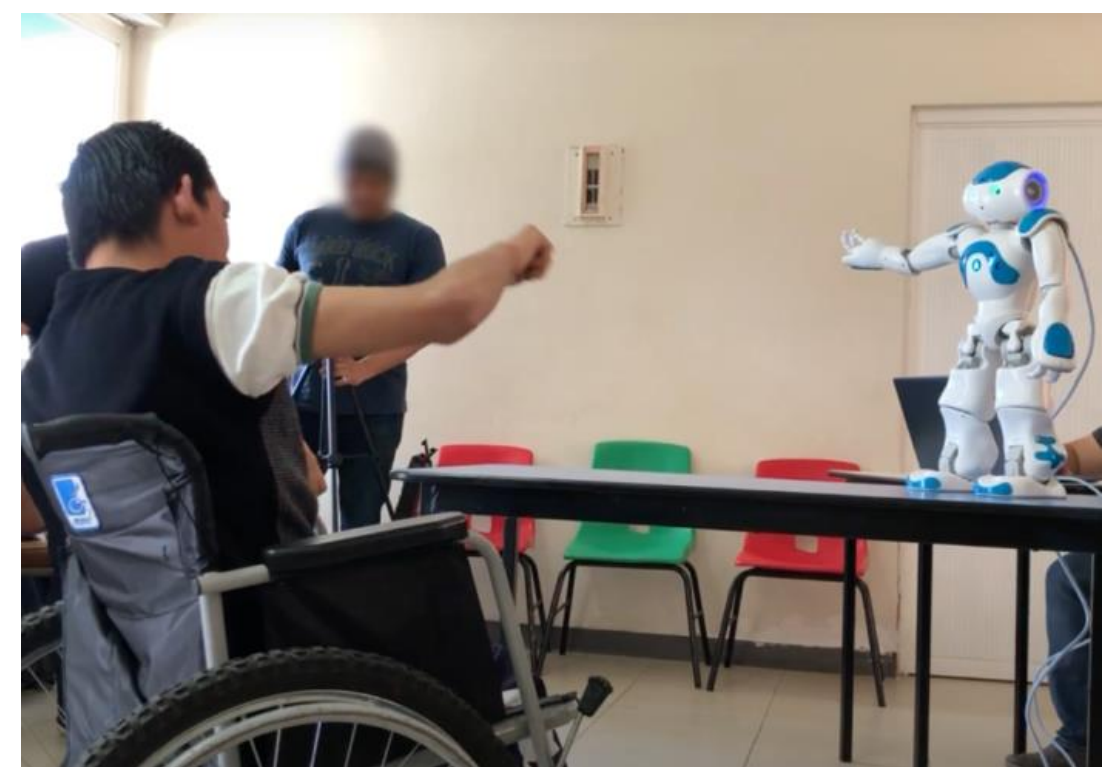

Figure 3. Arm lifting routine

While considering the possible scenarios in which the robot would interact, students faced the challenge of making the therapy session similar to a typical, solely human therapy session. Therefore, they made a series of assumptions regarding the patient's attention span, questions that the patient could ask and how a regular conversation could generate empathy and make the patient feel comfortable.

To overcome this challenge, the students developed a complete routine for the therapy, as shown in Figure 4.

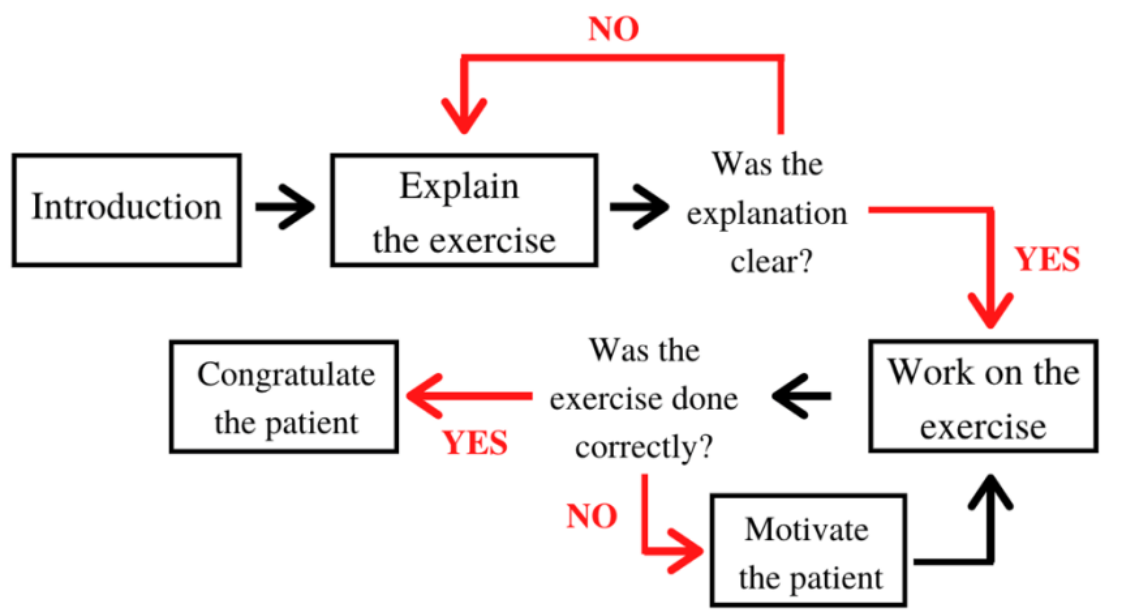

Figure 4. Therapy diagram

The robot starts trying to catch the patient's attention by introducing itself and asking about their day. After the introduction, the robot leads the conversation to the beginning of the therapy. It starts explaining the exercises, always asking the patient if the explanations are straightforward, so it could repeat them if necessary. Furthermore, during the entire process of working on the exercise, the robot tries to interact with the patient by using motivational phrases such as "keep going, you are doing amazing!" and "you are too good at this!". According to the study by Jimenez et al. (2020), the use of this type of interaction facilitates the improvement of learning and student learning motivation; therefore, the undergraduate students decided to include praise in their project. Finally, once the exercise is done, the robot either congratulates the patient if the exercise is successfully done or motivates them to repeat it if there is any misunderstanding or failure to complete the exercise.

This iterative process ends when the patient completes the exercises or when the therapy is over. Also, the therapist attending the session has total freedom to stop the session when they deem it necessary. 


\section{Usability measurement of the platform}

As mentioned before, one of the most acceptable ways of measuring the level of acceptance of a robotic platform is using the simplified UTAUT model described in the study of Heerink et al. (2009). For this reason, we modified the 40 questions to suit our purpose. The questions are shown in Table 2, indicating the evaluation of each of the ten constructs. Every question was evaluated with a 7-point Likert scale, with 1 being the equivalent of disagreeing entirely with the question and 7 totally agreeing with it. In the case of the anxiety construct, the Likert scale was inversed since it evaluates a negative perspective of the platform's use.

The sample consisted of the eight students who participated in the robot's programming and implementation during the therapy sessions and the five members of the medical staff of FADEM who interacted through the development of the whole project. In addition, the platform's general usability was evaluated through the Cronbach's alpha metric to perceive the reproducibility of each construct and the general questionnaire. All the students and medical staff gave verbal consent to use the data obtained in the questionnaire.

Table 2

Usability questionnaire

\begin{tabular}{|c|c|}
\hline Construct & Question \\
\hline ANX & $\begin{array}{l}\text { I am worried about making a mistake when using the robot. } \\
\text { I am worried about breaking the robot when using it. } \\
\text { The robot scares me and or the patient. } \\
\text { The robot intimidates me and or the patient. }\end{array}$ \\
\hline $\mathrm{FC}$ & $\begin{array}{l}\text { I have enough material to make good use of the robot. } \\
\text { I have enough knowledge to use the robot. }\end{array}$ \\
\hline PAD & $\begin{array}{l}\text { I consider that the robot is capable of adapting to my necessities. } \\
\text { I consider that the robot will only work as needed at a particular moment. } \\
\text { I consider that the robot will be helpful when I deem it necessary. }\end{array}$ \\
\hline PENJ & $\begin{array}{l}\text { I like the robot talking with the patient. } \\
\text { The patient likes doing activities with the robot. } \\
\text { The robot is entertaining. } \\
\text { The robot is fascinating. } \\
\text { The robot is dull. } \\
\text { The expectancies towards the robot were accomplished. } \\
\text { It would have been better if the robot had more interactions. }\end{array}$ \\
\hline PEOU & $\begin{array}{l}\text { I consider that I learned fast enough how to use the robot. } \\
\text { The robot is easy to use. } \\
\text { I can use the robot without help. } \\
\text { I can use the robot when someone is helping me with it. } \\
\text { I could use the robot if I had a user's guide. }\end{array}$ \\
\hline PS & $\begin{array}{l}\text { The robot is a great conversational partner. } \\
\text { I like interacting with the robot. } \\
\text { It appears that the robot understands the patient. } \\
\text { The robot is cute. } \\
\text { The robot's interactions achieved my expectancies. }\end{array}$ \\
\hline PU & $\begin{array}{l}\text { The robot is helpful. } \\
\text { It is convenient to have the robot always. } \\
\text { The robot can help me with many tasks. } \\
\text { The sessions are easier when using the robot. } \\
\text { The session's quality improves when using the robot. } \\
\text { The robot is an ideal didactic tool for the sessions. } \\
\text { The sessions are more didactic when using the robot. }\end{array}$ \\
\hline SI & $\begin{array}{l}\text { My superiors would like me to use the robot. } \\
\text { The use of the robot will generate a good impression of me in future sessions. }\end{array}$ \\
\hline SP & $\begin{array}{l}\text { When using the robot, it looks like it is interacting with a person. } \\
\text { I felt that the robot was watching the patient or me. } \\
\text { It looks like the robot has genuine emotions. }\end{array}$ \\
\hline Trust & $\begin{array}{l}\text { The patient would trust the robot's advice. } \\
\text { The patient follows the robot's instructions without any problem. }\end{array}$ \\
\hline
\end{tabular}

Note. Construct names in order from top to bottom: anxiety, facilitating conditions, perceived adaptability, perceived enjoyment, perceived ease of use, perceived sociability, perceived usefulness, social influence, social presence and trust. 


\section{Analysis of results}

After each of the eight students answered the questionnaire, the Cronbach's alpha metric was used to evaluate the constructs and the general test reproducibility. The general results are shown in Table 3. Since the results show low values of Cronbach's alpha, it is not possible to verify if this methodology can generate the same results in a different scenario or with another population.

However, the general observations of the students and medical staff indicate the usability of the robotic platform for a specific use. Considering the constructs with the bigger Cronbach's alpha, the results in Table 3 show that the implementation during the rehabilitation sessions was adequate for the given environment. At the same time, the robotic platform was considerably easy to program and implement, thanks to the collaboration between the students and the medical staff who supported each session's programming.

There was also a consensus between the patients regarding the robot's social influence during the sessions, demonstrating an increasing interest in using new platforms that can help improve the quality of the sessions. This result plays an important role in this study, demonstrating that not only was there a mutual interest between the students and the FADEM staff to improve the collaboration, but also an interest from the patients to keep experiencing new methodologies using social robotics.

Finally, when evaluating only the mean and standard deviation of the results, the robot is considered capable of adapting to the given situation, making it easier to interact with different patients without changing the session's routine. Furthermore, there was also consensus on the robot's usability during the therapy sessions since the robot could solve the given tasks, improving the quality of the sessions.

Table 3

General results from the questionnaire

\begin{tabular}{lccccc}
\hline Construct & Min & Max & Mean & SD & Cronbach's alpha \\
\hline ANX & 1 & 7 & 5.73 & 1.7835 & -0.13 \\
FC & 3 & 7 & 6.00 & 1.0583 & -0.07 \\
PAD & 4 & 7 & 6.28 & 0.7591 & -0.08 \\
PENJ & 1 & 7 & 5.73 & 2.0980 & -0.14 \\
PEOU & 1 & 7 & 5.65 & 1.6529 & -0.05 \\
PS & 4 & 7 & 6.22 & 0.9269 & -0.13 \\
PU & 4 & 7 & 6.66 & 0.6186 & -0.09 \\
SI & 6 & 7 & 6.88 & 0.3258 & 0.02 \\
SP & 1 & 7 & 4.77 & 1.2868 & -0.05 \\
Trust & 2 & 7 & 5.69 & 1.1582 & -0.11 \\
General test & 1 & 7 & 5.98 & 1.4676 & -0.11 \\
\hline
\end{tabular}

Note. Construct names in order from top to bottom: anxiety, facilitating conditions, perceived adaptability, perceived enjoyment, perceived ease of use, perceived sociability, perceived usefulness, social influence, social presence and trust.

\section{Conclusions}

Since this involved using a robotic platform in a real rehabilitation session scenario, it was not possible to evaluate a more significant population of students or patients, considering that interaction with the latter is regulated. However, thanks to the medical staff's control and observation in collaboration with the students, it was possible to observe how well a robotic platform performs in a real-world scenario.

The results from the Cronbach's alpha evaluation show that cannot be implemented in more environments since the results are not reproducible. However, this academic experience demonstrates that using a robotic platform for interacting with patients in a medical real-case scenario is viable since there is no perceived anxiety from the patients when using the robot. A significant measurement of perceived usability and social influence was obtained as well.

The evaluation of Cronbach's alpha and the usability of the platform are two separate metrics, one does not depend on the other. The Cronbach's alpha measurement evaluates if the results can be reproduced with a different population in case the experiment is repeated in the future, while the usability test measures the perception of the population involved in this experiment. Considering this, it is acceptable to report both 
analyses here since it is important to evaluate if these experiments will produce similar results in the future, as well as evaluate the perception of those involved.

The sample of students could not be larger since it was necessary to control the number of people who interacted with the patients to ensure their safety during each therapy session.

This shows how it is possible to establish a project-based learning methodology for undergraduate students and implement their knowledge into a problem, with the difficulties and tasks required for a real-world implementation: a therapy methodology that improves the rehabilitation process. FADEM staff supervised the design process while also being responsible for determining the standards needed for the therapy to be considered beneficial.

The university's collaboration with professional therapists allows undergraduate students to implement their technical knowledge to solve a particular problem, giving a practical context to the content studied in class. It allows students to experience a new educational approach that not only challenges them in terms of the topics learned in class but also places them in a completely new situation, where their final product is meant to help people. Creating a project that has a real social impact encouraged the students to question themselves, build empathy and work harder during the entire process to generate a final product that could cause the best positive impact. The benefits of project-based learning with a focus on solving real-life situations go beyond the technical. The social skills that students develop with these approaches are those necessary to become professionals with the ability to empathise and seek the benefit of their surroundings.

\section{Acknowledgements}

We would like to thank the Foundation to Help the Mentally Weak in Mexico City for collaborating in developing this academic experience. We would also like to acknowledge the financial and technical support of Writing Labs, TecLabs, Tecnologico de Monterrey, Mexico, in the production of this paper.

\section{References}

Ahmad Zukarnain, Z., Wan Husain, W. S., Che Hassan, S. H., Nik Kamaruzaman, N. N., Mohd Zin, N. A., \& Wan Aziz, W. A. H. (2020). Examining students' aptitude using project-based learning through university-industry collaboration. Journal of Physics: Conference Series, 1496(1), Article 012013. https://doi.org/10.1088/1742-6596/1496/1/012013

Aizpun, M., Sandino, D., \& Merideno, I. (2015). Developing students' aptitudes through universityindustry collaboration. Ingenieria e Investigacion, 35(3), 121-128. https://doi.org/10.15446/ing.investig.v35n3.48188

Al Mulhim, E. N., \& Eldokhny, A. A. (2020). The impact of collaborative group size on students' achievement and product quality in project-based learning environments. International Journal of Emerging Technologies in Learning, 15(10), 157-174. https://doi.org/10.3991/ijet.v15i10.12913

Andreasson, R., Alenljung, B., Billing, E., \& Lowe, R. (2018). Affective touch in human-robot interaction: Conveying emotion to the Nao robot. International Journal of Social Robotics, 10(4), 473-491. https://doi.org/10.1007/s12369-017-0446-3

Assad-Uz-Zaman, M., Islam, M. R., Rahman, M. H., Wang, Y. C., \& McGonigle, E. (2020). Kinect controlled NAO robot for telerehabilitation. Journal of Intelligent Systems, 30(1), 224-239. https://doi.org/10.1515/jisys-2019-0126

Belpaeme, T., Kennedy, J., Ramachandran, A., Scassellati, B., \& Tanaka, F. (2018). Social robots for education: A review. Science Robotics, 3(21), 1-10. https://doi.org/10.1126/scirobotics.aat5954

Bilgin, I., Karakuyu, Y., \& Ay, Y. (2015). The effects of project based learning on undergraduate students' achievement and self-efficacy beliefs towards science teaching. Eurasia Journal of Mathematics, Science and Technology Education, 11(3), 469-477. https://doi.org/10.12973/eurasia.2014.1015a

Borisova, E. N., \& Letkina, N. V. (2019). English for professional communication: A project-based approach to teaching university students (A case study of music students). Integration of Education, 23(4), 607-627. https://doi.org/10.15507/1991-9468.097.023.201904.607-627

Carrasco, A., Donoso, J. A., Duarte, T., Hernández, J., \& López Gavira, R. (2018). The effectiveness of the project-based learning (PrjBL) approach in undergraduate accounting education. EDUCADE - 
Revista de Educación En Contabilidad, Finanzas y Administración de Empresas, 9, 659-683. https://doi.org/10.12795/educade.2018.i09.05

Chen, M., Wang, L., Xu, C. Z., \& Li, R. (2017). A novel approach of system design for dialect speech interaction with NAO robot. In Proceeding of the 18th International Conference on Advanced Robotics (pp. 476-481). IEEE. https://doi.org/10.1109/icar.2017.8023652

Davis, F. D. (1989). Perceived usefulness, perceived ease of use and user acceptance of information technology. MIS Quarterly, 13(3), 319-340. https://doi.org/10.2307/249008

Donnermann, M., Schaper, P., \& Lugrin, B. (2020). Integrating a social robot in higher education-a field study. In Proceeding of the 29th IEEE International Conference on Robot and Human Interactive Communication (pp. 573-579). IEEE. https://doi.org/10.1109/RO-MAN47096.2020.9223602

Goenaga, S., Navarro, L., Quintero, C. G. M., \& Pardo, M. (2020). Imitating human emotions with a NAO robot as interviewer playing the role of vocational tutor. Electronics (Switzerland), 9(6), 1-25. https://doi.org/10.3390/electronics9060971

Heerink, M., Krose, B., Evers, V., \& Wielinga, B. (2009). Measuring acceptance of an assistive social robot: a suggested toolkit. In Proceeding of the 18th IEEE International Symposium on Robot and Human Interactive Communication (pp. 528-533). IEEE. https://doi.org/10.1109/ROMAN.2009.5326320

Jimenez, F., Kanoh, M., Yoshikawa, T., \& Nakamura, T. (2020). Learning effect of collaborative learning with robots speaking a compliment. Journal of Advanced Computational Intelligence and Intelligent Informatics, 24(3), 396-403. https://doi.org/10.20965/jaciii.2020.p0396

Johal, W. (2020). Research trends in social robots for learning. Current Robotics Reports, 1(3), 75-83. https://doi.org/10.1007/s43154-020-00008-3

Kovalyova, Y. Y., Soboleva, A. V., \& Kerimkulov, A. T. (2016). Project based learning in teaching communication skills in English as a foreign language to engineering students. International Journal of Emerging Technologies in Learning, 11(4), 153-156. https://doi.org/10.3991/ijet.v11i04.5416

Nurbekova, Z., Tolganbaiuly, T., Nurbekov, B., Sagimbayeva, A., \& Kazhiakparova, Z. (2020). Projectbased learning technology: An example in programming microcontrollers. International Journal of Emerging Technologies in Learning, 15(11), 218-227. https://doi.org/10.3991/IJET.V15I11.13267

Pot, E., Monceaux, J., Gelin, R., \& Maisonnier, B. (2009). Choregraphe: A graphical tool for humanoid robot programming. In Proceeding of the 18th IEEE International Symposium on Robot and Human Interactive Communication (pp. 46-51). IEEE. https://doi.org/10.1109/ROMAN.2009.5326209

Reyes, G. E. B., López, E., Ponce, P., \& Mazón, N. (2021). Role assignment analysis of an assistive robotic platform in a high school mathematics class, through a gamification and usability evaluation. International Journal of Social Robotics, 13(5), 1063-1078. https://doi.org/10.1007/s12369-02000698-x

Sakulvirikitkul, P., Sintanakul, K., \& Srisomphan, J. (2020). The design of a learning process for promoting teamwork using project-based learning and the concept of agile software development. International Journal of Emerging Technologies in Learning, 15(3), 207-222. https://doi.org/10.3991/ijet.v15i03.10480

Shamsuddin, S., Yussof, H., Ismail, L., Hanapiah, F. A., Mohamed, S., Piah, H. A., \& Zahari, N. I. (2012). Initial response of autistic children in human-robot interaction therapy with humanoid robot NAO. In Proceedings of the IEEE 8th International Colloquium on Signal Processing and Its Applications (pp. 188-193). https://doi.org/10.1109/CSPA.2012.6194716

Smakman, M. H. J., Konijn, E. A., Vogt, P., \& Pankowska, P. (2021). Attitudes towards social robots in education: Enthusiast, practical, troubled, sceptic and mindfully positive. Robotics, 10(1), 1-21. https://doi.org/10.3390/robotics10010024

van Wynsberghe, A. (2016). Service robots, care ethics and design. Ethics and Information Technology, 18(4), 311-321. https://doi.org/10.1007/s10676-016-9409-x

Venkatesh, V., Morris, M. G., Davis, G. B., \& Davis, F. D. (2003). User acceptance of information technology: Toward a unified view. MIS Quarterly, 27(3), 425-478. https://doi.org/10.2307/30036540

Wadkar, S. K., Singh, K., Chakravarty, R., \& Argade, S. D. (2016). Assessing the reliability of attitude scale by Cronbach's alpha. Journal of Global Communication, 9(2), 113-117. https://doi.org/10.5958/0976-2442.2016.00019.7

Wang, Y.-H. (2020). integrating games, e-books and AR Techniques to support project-based science learning. Educational Technology \& Society, 23(3), 53-67. https://drive.google.com/file/d/1nPIJNtTMAMD1tpdrOoc36BNxqLtF9RuP/view?usp=sharing 
Wurdinger, S., Newell, R., \& Kim, E. S. (2020). Measuring life skills, hope and academic growth at project-based learning schools. Improving Schools, 23(3), 264-276.

https://doi.org/10.1177/1365480220901968

Zarouk, M. Y., Olivera, E., \& Khaldi, M. (2020). The impact of flipped project-based learning on selfregulation in higher education. International Journal of Emerging Technologies in Learning, 15(17), 127-147. https://doi.org/10.3991/ijet.v15i17.14135

Corresponding author: J. Enrique Chong-Quero, jchong@tec.mx

Copyright: Articles published in the Australasian Journal of Educational Technology (AJET) are available under Creative Commons Attribution Non-Commercial No Derivatives Licence (CC BY-NC-ND 4.0). Authors retain copyright in their work and grant AJET right of first publication under CC BY-NC-ND 4.0.

Please cite as: Lopez-Caudana, E., Lopez-Orozco, C. F., Mendoza, C., Reyes, G. E. B., Ponce, P, \& Chong-Quero, J. E. (2021). Physical therapy using robotics: A project-based learning experience for undergraduate students. Australasian Journal of Educational Technology, 37(5), 32-42.

https://doi.org/10.14742/ajet.7139 